\section{HAND CRUSHED: INFECTED WITH GAS BACILLUS OF MALJGNANT EDEMA}

\section{A.IPCTATIOA OF FOREARM : RECOVERY *}

\section{G. PAUL LAROQUE, M.D. RICHMOND, VA.}

Were it not for the fact that the patient recovered from an infection which is alleged to be almost uniformly fatal, a single case report of an extremely rare infection would scarcely be worth while. On account of the fact, however, that patients infected by the socalled gas-producing bacillus of malignant edema nearIy always die, even after the most radical and high amputations, a case of recovery following conservative treatment slould be recorded.

Until the present case came under my observation I had seen only one case. This occurred in the practice $n t$ my former chief, Dr. Edward Martin, of Philadelphia. 'The patient was a young woman who suffered a compound fracture of the ankle and died within three days in spite of amputation at the hip joint. Another case occurred in the Lniversity Hospital in Philadelphia a short time before my period of service as resident surgeon in that institution, and this patient died in spite of high amputation. The following case is the only one I have heard of in Virginia in which the organism was demonstrated bacteriologically:

Injury.-R. C., a colored man, aged 32 , while engaged in shucking corn with a machine on a farm about ten miles from Richmond, suffered a severe crushing of the left hand. $\mathrm{He}$ was at once referred by Dr. W. A. Campbell to Dr. Stuart MeGuire's clinic at the Virginia Hospital. On examination of the injury by the resident surgeon, Dr. W. D. Carr, it was obvious that, on account of the extensive injury of the hand and wrist, amputation was indicated. I saw the patient about $8 \mathrm{p} . \mathrm{m}$. of the day of admission. There was extensive mutilation of all the soft parts and bones of the hand and wrist and the tissues injured had already become black and obviously gangrenous. There was the characteristic gangrenous odor, and the hand and soft parts were infiltrated with gas to about two inches above the wrist. A diagnosis of gas-bacillus infection was at once made. A smear from the injured hand. examined microscopically by Dr. Guy Hopkins and Dr. G. H. Baerecke, showed the characteristic organism of malignant edema, together with some mixed infection.

Treatment.-Amputation of the middle of the forearm was at once performed by the resident surgeons, Drs. Carr and Booker, under my instruction. The next day the stump appeared black in color and a foul odor was emitted. Some of the bloody discharge from the stump was examined microscopically and the bacillus of malignant edema was found to be present. This caused us immediate alarm, and we at once took into consideration higher amputation. The patient's temperature was 103 , pulse 120 . In order to determine whether or not the infection was limited to the stump or whether it was being conveyed into the general circulation, we secured blood from the regional veins leading from the stump and also from the veins of the opposite elbow. Both of these specimens were submitted to the bacteriologists for examination, and in neither specimen was the organism present. Believing that consultation should always be held before any amputation is done, I called Dr. W. Lowndes Peple to see the patient. After discussing the matter for about half an hour, we concluded that, inasmuch as the patient's general condition was good and the local condition of the arm above the stump was good, higher amputation would not be justifiable. We therefore removed all the stitches and left the wound wide open to be treated with antiseptics and oxidizing agents, since it is a well-known fact that these organisms do not live in the presence of oxygen. Local applications of hydrogen

* Reported at the Richmond Academy of Medicine and Surgery, January, 1909 . peroxid, potassium permanganate and oil of turpentine were made to the raw surface and the stump enveloped with a dressing wet with 1 per cent. solution of chloral hydrate. The next day we made another examination of the blood leading from the stump and found it sterile. Two days later smears were made of the discharge from the stump and the bacillus of malignant edema was not to be found. The patient's condition remained good and recovery ensued as soon as could have been expected from a suppurating wound.

219 East Grace street.

\section{EXFOLIATIVE NEONATAL DERMATITIS}

\section{J. C. MATTHEWS, M.D SPRINGEIELD, MO.}

The object in reporting this case, which might be termed dermatitis exfoliativa prenatal rather than neonatal, is to call attention to the undoubted development of this disease, or condition in utero.

Ritter, in 1878 , was the first to call definite attention to this condition; but in all cases reported by him and others since that time I failed to find a case reported as existing at birth. From two to five weeks after birth is given as the usual time of development of symptoms.

Patient.-Baby R., male, was born at term, Feb. 8, 1909; normal labor; weight was $61 / 2$ pounds; the ehild was welldeveloped and seemingly of good vitality, as he breathed and cried well.

Condition at Birth. - When the arms and hands were delivered I noticed an unusual condition of hands, and on careful inspection of ehild, after delivery, I discovered that the hands and feet were denuded of epidermis. This condition included the fingers and toes, except their tips, and back to the wrists and ankles. The nose, penis and margin of umbilicus were also denuded, appearing dark red, not unlike a burn of the second degree caused by steam or hot water. The lesions were exuding serum as would a burn, and shreds of cuticle were hanging at the margins.

Treatment and Course of Disease.-The child was dressed and put to breast, which it nursed in a normal way. The raw surfaces were dressed with boric acid and sweet oil. On February $9 \mathrm{I}$ saw the child in company with Dr. Anderson; we found it in a weakened condition, its face pinched and drawn, the clothing and bandages saturated with serum, and with some bleeding from the nose and margin of the umbilicus. We also found, on dressing it, that the exfoliation had extended up the arms and legs for from one to one and a half inches, and in pockets under the cuticle a clear serum similar to a blister caused by a burn was found. During the past twenty-four hours the child had nursed a little, bowels had acted, urine had been voided, and the child had cried a great deal. Temperature was 97 in the rectum.

February 10: The child was much weakened, it had not nursed since the last visit. The clothing and bandages were saturated and stiff with serum and blood; the surface of the body was cold, skin was pale and wrinkled; breathing was shallow. The heart sounds were weak, and attempts to ery produced only a weak moan.

During the night the child died. No postmortem examina tion was made.

History of Parents.-The mother was a decided blond, well developed, weight 118 pounds, age 18. This was her first child. Labor and recovery were normal. History of herself and parents was good, though she sunburns easily. The father is a medium blond, aged 21 , healthy and hearty; weight 145 pounds. There is no history of syphilis or hereditary disease on either side.

Purity and Digestibility of Foods.-..."The first requisite which we should make for foods for invalids is that they should be pure. The next most important thing is to find a pure food which the invalid can digest."....H. W. Wiley in the New York Hedical Journal. 